\title{
Active Power and Cost Allocation in Open ACCESS ENVIRONMENT UTILIZING POWER Flow TraCiNg METHOD CONSIDERING N-1 CONTINGENCY CONDITION
}

\author{
Pawan Rathore ${ }^{1}$, Garima Naidu ${ }^{2}$, Ganga Agnihotri ${ }^{3}$ and Baseem Khan ${ }^{4}$ \\ ${ }_{1,2,3,4}$ Department of Electrical Engineering, MANIT, Bhopal, India
}

\begin{abstract}
The transmission usage cost allocation is one of the major issues experienced by the Electric Supply Industries. In this paper, authors have considered Line Outage Distribution Factor (LODF) for allocating the transmission usage cost allocation under contingency condition. Authors have modified the distribution factor for maximum flow and propose a novel Maximum Line Outage Distribution Factor $(M L O D F)$ which depends upon the redistribution of the generation in the line flow considering $N-1$ security constraints. Similarly, for transmission loss cost allocation under contingency condition Maximum Line Outage Loss Distribution Factor (MLOLDF) is developed. Full recovery policy of transmission cost allocation is considered. The reliability and accuracy of the proposed method is tested on the sample 6 bus system.
\end{abstract}

\section{KEYWORDS}

LODF, MLODF, MLOLDF, MW-Mile method, Transmission cost allocation, Transmission loss cost allocation, Transmission Pricing.

\section{NOMENCLATURE}

$P_{i, m} \quad$ Power flow in the line i after an outage in the line $m$.

$P_{i} \quad$ Normal power flow in the line $i$.

$T C_{t} \quad$ Cost allocated to network user $t$.

TC Total transmission usage cost.

TLC Total transmission loss cost.

$P_{t} \quad$ Power of user $t$ at the time of system peak.

$P_{\max } \quad$ System maximum load.

$C_{k} \quad$ Cost per MW per unit length of line $k$.

$L_{k} \quad$ Length of the line $k$.

$M W_{t, i} \quad$ Power flow in the line $i$ due to user $t$.

$F_{t, i} \quad$ Power flow on the facility $i$ caused by user $t$.

$F_{\max , i} \quad$ Capacity of facility $i$.

$F_{\text {opt }, k} \quad$ Optimal capacity of transmission line $k$.

$p_{-}$line $_{i} \quad$ Power flow in the line $i$.

$p l_{-}$line ${ }_{i} \quad$ Power loss in the line $i$.

$K_{m} \quad$ Modified Kirchhoff Matrix.

I Identity Matrix

$P_{G} \quad$ Total active power of generators.

DOI : 10.14810/ecij.2014.3203 
Electrical \& Computer Engineering: An International Journal (ECIJ) Volume 3, Number 2, June 2014

$P_{L} \quad$ Total active power of loads.

\section{INTRODUCTION}

Electricity growth is very important for any country's development. Transmission System plays a vital role in the power system. It is considered as the backbone of the system. In every country transmission system is considered natural monopoly. The transmission usage and cost is allocated on a non discriminate basis depending on the actual power flows and point of interconnection. If any new generation is coming up, then it has to first plan for evacuation of power to the grid. Now due to deregulation in the electric market, the transmission system has been opened to private participants. Electricity has become commodity; one can buy or sell the electricity. Transmission pricing technique should be sufficient to fulfill following issues:

- Transmission pricing method should be non-discriminatory in nature.

- Charges to all generators and loads are in a comparable manner.

- It should be able to recover the full fixed cost of the transmission system.

- There should be proper monitoring in the branch flows.

- It should periodically update the transmission system cost.

- It should be able to encourage new generators to be established.

Electric utilities traditionally allocate the transmission cost to each generator and load based on Postage Stamp and Contract Path methods [1]. In the Postage Stamp method, transmission network users are charged based on an average cost and the magnitude of the allocated power. On the other hand, in the Contract Path method, power is confined to flow along an artificially specified path. Based on the calculation of the actual extent of use of the transmission network MW Mile method is proposed [2], [3]. The cost depends upon the magnitude, the path and the distance travelled by the transacted power. Various modified MW Mile methodologies have been proposed in the literature [4-7].

Tsukamoto and Iyoda [11] introduced the concept of cooperative game theory for fixed-cost allocation to wheeling transactions in a power system. Yu et al. [12] presented a method for transmission embedded cost allocation based on the use of line capacity. Tan and Lie [13] applied the Shapley value approach for the transmission network cost allocation. Zolezzi and Rudnick [14] allocated the cost of existing or expanding the network based on a model that integrates cooperation and coordination among the agents with solutions based on the Nucleolus and Shapley value approaches. Yu et al. [15] allocated the capacity-use and reliability-based transmission embedded cost using the Nucleolus and Shapley value concept. Stamtsis and Erlich [16] analyzed the cost allocation problem for the fixed cost of a power system and realized that the Shapley value is preferable when it lies in the core of the game [17].

In Aug 2013, Orfanos et al. [18] explained a power flow based method to allocate the transmission fixed cost in a pool based electricity market considering contingencies. They considered that the possible maximum used capacity of a transmission network is the maximum power flow during contingency analysis. The first attempt to trace real and reactive power flow was done by Bialek et al. [19] when Topological Generation Distribution factors based Power flow tracing were proposed in March 1996 which explained the method for tracing generators' output. Proportional Sharing method was used to trace the flow of electricity. Distribution factors [20] are defined by sensitivity analysis relating a change in power injection at a certain bus to a change in the power flow on a particular line. In 1996, Bialek [20] presented a method which allows allocating the supplement charge for transmission services to individual load or generator. Topological factor represents the share of the load in a power flow while the generalized factor 
shows the impact of the load on the power flow. Generalized Generation / Load Distribution Factors (GGDFs/GLDFs) are dependent upon line parameter not on the reference bus position.

In Feb 1997, Kirschen et al. [21] introduced a power flow tracing method based on the proportional sharing assumption which introduced the concept of domains, commons, and links. In Nov 2000, Gubina et al. [22] presented a new method to determine the generators' contribution to a particular load by using the nodal generation distribution factors (NGDF-s). The method also handled the reactive power. In Aug 2000, Felix et al. [23] proposed the use of graph theory to calculate the contributions of individual generator and load to line flows and the real power transfer between individual generator and load. A matrix inverse calculation is required which is a time taking process for a large power system.

In 2008, Xie et al. [24] proposed and explained the power flow tracing algorithms found in the Extended Incidence Matrix (EIM) considering loop flows. Charges had been allocated to generators and loads in 50:50 ratios. In Feb 2007, Conejo et al. [25] proposed a method of network cost allocation based on Z-bus matrix. In Aug 2006, Abhyankar et al. [26] proposed real power flow tracing method based on linear constrained optimization approach. They introduced a modified postage stamp method which evaluates a traceable solution that minimizes overall deviation from the postage stamp allocation. In Aug 2010, Rao et al. [27] explained the Min-Max fair allocation criteria for transmission system usage allocation.

In 2004, P. N. Biskas et al. [28] proposed a security constrained optimal power flow (SC-OPF) solution to trace each user's contribution to the line flows of the network. For this, first usage and then TRM allocation was done. In 1998, Silva et al. [29] considered the transmission network operation under normal as well as contingency condition for allocating cost to generators. In July 2004, D. Hur et al. [30] proposed various methods to allocate reliability contribution to market participants.

In June 2010, V. Vijay et al [31] proposed a novel probabilistic transmission pricing methodology with consideration of transmission reliability margin. In 2008, H. Monsef et al. [32] presented the transmission cost allocation based on use of reliability margin under contingency condition. For this purpose a probability index was defined. The cost of the unused facility under normal system operation, i.e. the reliability margin cost has been proposed in [33$35]$ to be allocated to transmission users following a contingency analysis.

In this paper, authors has presented a technique for allocating the usage and cost of the transmission system based on Shapley Value and power flow tracing method (Proportional Sharing). Different recovery policies for allocating the usage and cost are as follows:-

- Allocating $100 \%$ usage and cost to all loads.

- Allocating $100 \%$ usage and cost to all generators.

- Allocating 50\% - 50\% usage and cost to all generators and loads respectively.

- Allocating 33\% - 67\% usage and cost to all generators and loads respectively.

- Allocating $23 \%$ - $77 \%$ usage and cost to all generators and loads respectively.

In this paper, authors has considered $100 \%$ usage and cost allocation to all loads only. In this paper, Line Outage Distribution Factor (LODF) [35] and proposed Maximum Line Outage Distribution Factor (MLODF) are considered for transmission usage cost allocation. Network usage cost is determined by LODF and MLODF. MW-Mile method is used for proposed cost allocation method. Allocation to generators and loads is done by using modified Kirchhoff matrix methodology [6], [7]. Transmission pricing mechanism should be able to provide following signals: 
- If in any particular area the generation charges are high and there is adequate transmission capability, transmission charges will reduce by adding generation there.

- If in any particular area the generation charges are high and transmission system is operating close to capability, transmission charges will increase by adding generation there.

- If the demand is more near the generation hub, then the transmission charges due to flow of the power is low.

Figure 1. shows the process chart for the determination of transmission charges.

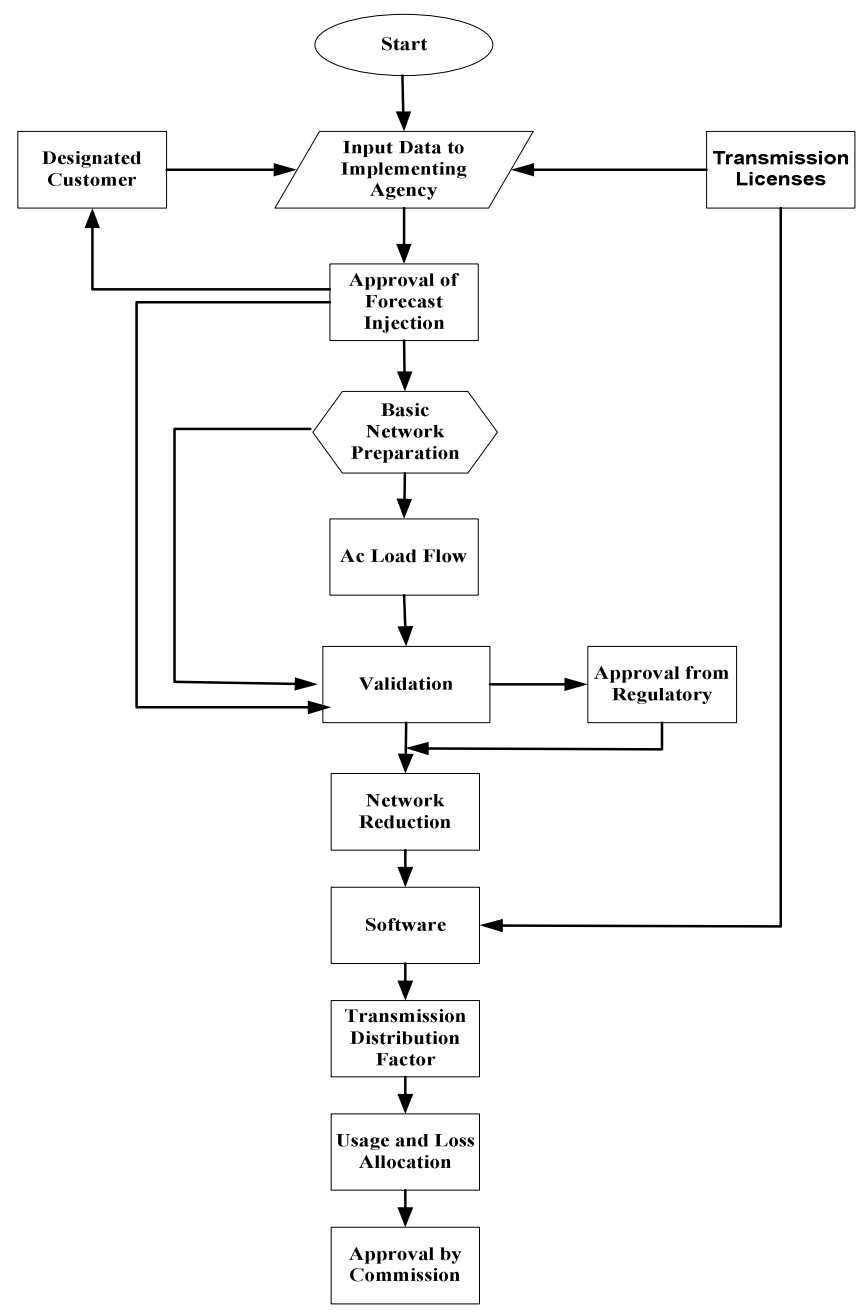

Figure 1. Process chart for the determination of transmission charges

\section{Power Flow Tracing Method}

Kirchhoff matrix is considered for power flow tracing [6]. In Modified Kirchhoff matrix the sum of all elements in the column $\mathrm{j}$ equals the total active power of generators at bus $j$ i.e.

$$
I^{T} K_{m}=\left(P_{G}\right)^{T}
$$


The above equation can be rewritten as follows:

$$
I=\left(K_{m}^{-1}\right)^{T} P_{G}
$$

From the above matrix, inverse of Modified Kirchhoff matrix $\left(\mathrm{K}_{\mathrm{m}}{ }^{-1}\right)$ is obtained which is used for power flow tracing. The active power distribution of $i^{\text {th }}$ generator is given as:

$$
P_{G i}=\sum_{j=1}^{n} t_{i j} P_{L j}
$$

where $t_{i j} P_{L j}$ denotes the active power distribution of generator output at bus $i$ to the load situated at bus $j[6]$. Thus

$$
P_{i \rightarrow j}=t_{i j} P_{L j}
$$

Eq. (4) gives the generators' share to loads in the system.

On the same line for calculating the generators' share to line flows Eq. (4) is modified by replacing load power from the line flows as shown in Eq.(5). For example, the generators' share situated at bus $\mathrm{s}$ to the line s-t is given by

$$
P_{i \rightarrow s-t}=t_{i s} P_{s t} a_{g}
$$

Hence Eq. (4) and Eq. (5) give the generators' share to loads and line flows. Similarly, the usage allocated to a load for the use of all lines can be defined by using $\mathrm{a}_{1}$ instead of $\mathrm{a}_{\mathrm{g}}$.

For calculating the loads' share in line flows and generated power, same procedure is followed. Consider dual of Eq. (2).

$$
P_{L}=P_{L L}\left(K_{m}^{-1}\right)^{T} P_{G}
$$

where the diagonal matrix $\mathrm{P}_{\mathrm{LL}}=\operatorname{diag}\left(\mathrm{P}_{\mathrm{L} 1}, \mathrm{P}_{\mathrm{L} 2}, \ldots, \mathrm{P}_{\mathrm{Ld}}\right)$ and $\mathrm{R}=\mathrm{P}_{\mathrm{LL}}\left(\mathrm{K}_{\mathrm{m}}{ }^{-1}\right)^{\mathrm{T}}$ is the extraction factor matrix of loads from generators [7].

By using an extraction factor matrix, loads' share in generating power and line flows is calculated.

For transmission loss allocations to generator, consider Eq. (5). In this equation, line flow $\mathrm{P}_{\mathrm{st}}$ is replaced by the transmission loss which is coming from the elements of the Kirchhoff loss matrix pli and $\mathrm{p}_{i}$.

Hence transmission losses of line s-t allocated to generator located at bus $i$ is given by:

$$
P_{i \rightarrow s-t}^{l}=t_{i s} P_{s t}^{l}
$$

Similarly, transmission losses of line s-t allocated to load situated at bus $\mathrm{j}$ is given by:

$$
P_{j \rightarrow s-t}^{l}=r_{j s} P_{s t}^{l}
$$


From Eq. (7) and Eq. (8) losses are allocated to generators and loads respectively. This method of loss allocation is said to be direct because all the calculation is already done for usage allocation.

\section{Transmission ACtive Cost Allocation}

Transmission usage cost allocation to users should be based on usage. The most common method used by electric utilities is Postage Stamp method. It depends upon the average system's cost and some factors which are usually the functions of the season, working day or holiday. The total transmission cost to network users using Postage Stamp method is as follows:

$$
T C_{t}=T C * \frac{P_{t}}{P_{\max }}
$$

In a power pool market, power flow based methods are used to calculate the contributions of each network user (generators or loads) to transmission lines by using power flow tracing algorithm [20] or the distributed factors [25]. After power flow allocation, network cost is allocated using MW Mile method [34].

In the MW Mile method, transmission usage cost allocation reflects the relative usage of the transmission network.

$$
T C_{t}=T C^{*} \frac{\sum_{k \in K} c_{i}^{*} L_{i} * M W_{t, i}}{\sum_{t \in T} \sum_{i \in I} c_{i} * L_{i} * M W_{t, i}}
$$

System charges can be evaluated based on either the unused or the used capacity. Full recovery of the transmission cost is guaranteed in the unused method. In the unused and used absolute methods, charges are calculated as follows:

$$
\begin{aligned}
T C_{t, a b s_{-} \text {unused }} & =\sum_{i \in I} C_{i} * \frac{\left|F_{t, i}\right|}{\sum_{t \in T}\left|F_{t, i}\right|} \\
T C_{t, a b s_{-} \text {used }} & =\sum_{i \in I} C_{i} * \frac{\left|F_{t, i}\right|}{F_{\max , i}}
\end{aligned}
$$

The optimal capacity of each line under contingency condition is given as:

$$
\begin{aligned}
& p_{-} \text {linef }_{i, m}=p_{-} \text {line }_{i}+\operatorname{LODF}_{i, m} * p_{-} \text {line }_{m} \\
& p_{-} \text {linef }_{i, m}=p_{-} \text {line }_{i}+\operatorname{MLODF}_{i, m} * p_{-} \text {line }_{m}
\end{aligned}
$$

The possible maximum usage capacity of each line is given as follows:

$$
F_{o p t, i}=\max \left(\mid p \_ \text {linef } f_{i, 1}|,|, p \_ \text {linef } f_{i, 2}|, \ldots| \underline{p} \_ \text {line } f_{i, I} \mid\right) * \frac{F_{i, \max }}{F^{c}{ }_{i, \max }}
$$


$\mathrm{F}_{\mathrm{i}, \max }^{\mathrm{c}}$ is the short term emergency rating of the line [18]. Due to optimal power flow in the line, the transmission usage cost to users is given as follows [18]:

$$
T C_{t, o p t}=\sum_{i \in I} C_{i} * \frac{\left|F_{t, i}\right|}{F_{o p t, i}}
$$

Total transmission loss cost to users is given as follows:

$$
T L C_{t, o p t}=\sum_{i \in I} C l_{i} * \frac{\left|F l_{t, i}\right|}{F l_{o p t, i}}
$$

\section{DistRIBUTION FACTORS}

During outage, the power flow in a line is different from that of normal conditions. The LODF is defined as the redistribution of the particular generation after an outage. Thus, Line Outage Distribution Factor is defined as the ratio of difference of the power flow in the line $i$ after an outage in the line $m$ and the normal power flow in the line $m$ to that of normal power flow in the line $i$ whereas MLODF is the ratio of difference in the power flow in the line $i$ after an outage in the line $m$ and the normal power flow in the line $m$ to that of maximum power flow in the line $i$ after an outage. The LODF is given by:

$$
L O D F=\left\{\frac{\left(P_{i, m}-P_{m}\right)}{P_{i}}, P_{i, m}>P_{i}\right\}
$$

The MLODF is given as:

$$
M L O D F=\left\{\frac{\left(P_{i, m}-P_{m}\right)}{P_{o p t, i}}, P_{i, m}>P_{i}\right\}
$$

For loss allocation, above two factors are modified as follows:

$$
L O L D F=\left\{\frac{\left(P l_{i, m}-P l_{m}\right)}{P l_{i}}, P l_{i, m}>P l_{i}\right\}
$$

The MLOLDF is given as:

$$
M L O L D F=\left\{\frac{\left(P l_{i, m}-P l_{m}\right)}{P l_{o p t, i}}, P l_{i, m}>P l_{i}\right\}
$$

Line Outage Loss Distribution Factor is defined as the ratio of difference of the power loss in the line $i$ after an outage in the line $m$ and the normal power loss in the line $m$ to that of normal power loss in the line $i$ whereas MLODF is the ratio of difference in the power loss in the line $i$ after an outage in the line $m$ and the normal power loss in the line $m$ to that of maximum power loss in the line $i$ after an outage. After calculating the distribution factors, maximum loss of each line is calculated using Eq. (24) and then the loss cost is allocated by using Eq. (17).

$$
\begin{aligned}
& p l_{-} \text {line } f_{i, m}=p l_{-} \text {line }_{i}+L O L D F_{i, m} * p l_{-} \text {line }_{m} \\
& p l_{-} \text {line }_{i, m}=p l_{-} \text {line } \\
& +
\end{aligned}
$$


The possible maximum loss of each line is given as follows:

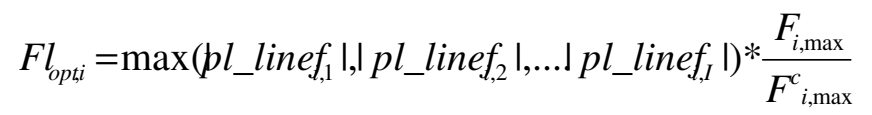

\section{Test ON SAMPLE 6 Bus System}

The feasibility and the efficiency of the proposed method are tested on the sample 6 bus system. Figure 2. shows the sample 6 bus system. It consists of three generator bus and three load bus. Table 1. shows the line data details of the 6 bus system.

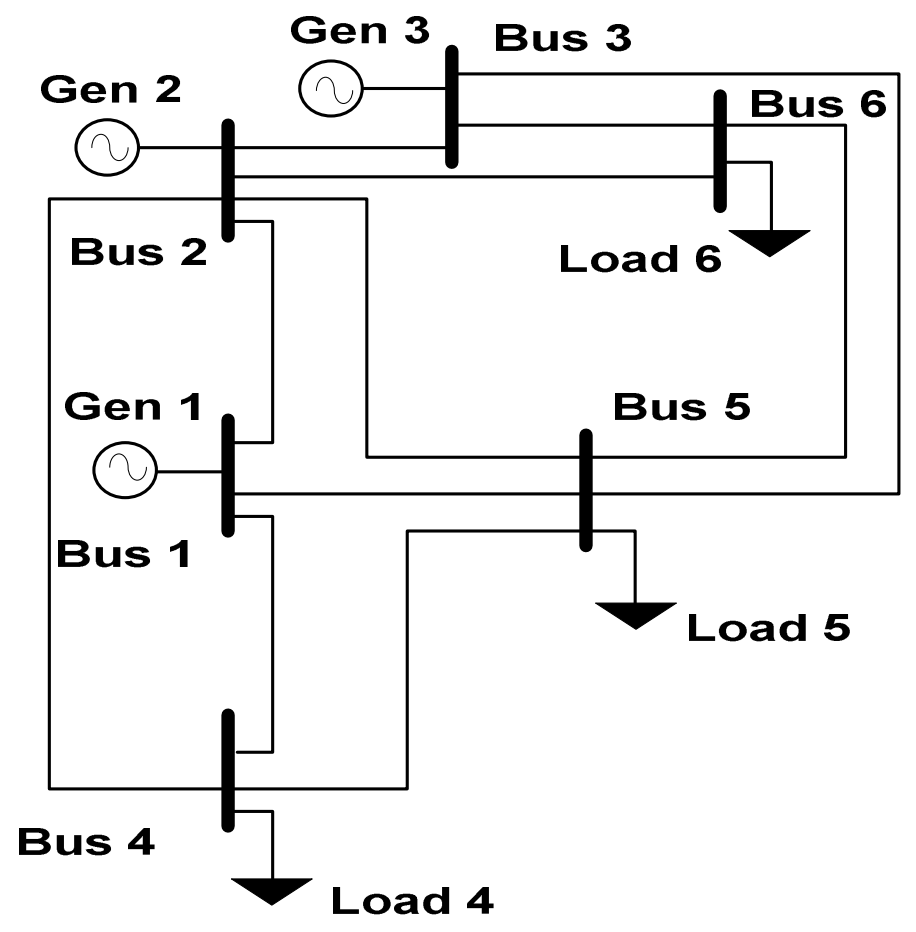

Figure 2. Sample 6 Bus System.

Table 1. Line data Details of the 6 Bus System

\begin{tabular}{|l|l|l|l|}
\hline Line & $\mathbf{R}$ (p.u.) & $\mathbf{X}$ (p.u.) & BL (p.u.) \\
\hline $1-2$ & 0.10 & 0.20 & 0.04 \\
\hline $1-4$ & 0.05 & 0.20 & 0.04 \\
\hline $1-5$ & 0.08 & 0.30 & 0.06 \\
\hline $2-3$ & 0.05 & 0.25 & 0.06 \\
\hline $2-4$ & 0.05 & 0.10 & 0.02 \\
\hline $2-5$ & 0.10 & 0.30 & 0.04 \\
\hline $2-6$ & 0.07 & 0.20 & 0.05 \\
\hline $3-5$ & 0.12 & 0.26 & 0.05 \\
\hline $3-6$ & 0.02 & 0.10 & 0.02 \\
\hline $4-5$ & 0.20 & 0.40 & 0.08 \\
\hline $5-6$ & 0.10 & 0.30 & 0.06 \\
\hline
\end{tabular}


The contribution of each generator and load is calculated with the help of Modified Kirchhoff matrix based power flow tracing method. Table 2. shows the total flows in the lines supplied by the different generators. In the first three lines it is observed that only Gen 1 is supplying power. Table 3. shows the total power is fully extracted by the different loads. It can be seen that the power extracted by Load 4 is lower than that of power extracted by loads of the lines 3-5, 3-6 and 5-6. For the line 4-5, entire power is extracted by the Load 6 only. The power flow in the lines 4-5 and 5-6 are extracted by a single load i.e. Load 4 and Load 5 respectively. For the line $2-3$, nearly equal power is extracted by the different loads. Table 4 . shows the loss allocation to different generators.

Table 2. Analysis of Flow to Generators for Sample 6 Bus System

\begin{tabular}{|l|l|l|l|l|}
\hline Line & $\begin{array}{l}\text { Flow } \\
(\mathbf{M W})\end{array}$ & $\begin{array}{l}\text { Supplied } \\
\text { by Gen 1 } \\
(\mathbf{M W})\end{array}$ & $\begin{array}{l}\text { Supplied } \\
\text { by Gen 2 } \\
(\mathbf{M W})\end{array}$ & $\begin{array}{l}\text { Supplied } \\
\text { by Gen 3 } \\
(\mathbf{M W})\end{array}$ \\
\hline $1-2$ & 29.1 & 29.07 & 0 & 0 \\
\hline $1-4$ & 43.7 & 43.66 & 0 & 0 \\
\hline $1-5$ & 35.6 & 35.56 & 0 & 0 \\
\hline $2-3$ & 3 & 1.12 & 1.92 & 0 \\
\hline $2-4$ & 33.3 & 12.4 & 21.3 & 0 \\
\hline $2-5$ & 15.5 & 5.77 & 9.91 & 0 \\
\hline $2-6$ & 26.4 & 9.83 & 16.88 & 0 \\
\hline $3-5$ & 19.3 & 0.34 & 0.59 & 18.4 \\
\hline $3-6$ & 43.6 & 0.77 & 1.32 & 41.56 \\
\hline $4-5$ & 4.2 & 3.17 & 1.21 & 0 \\
\hline $5-6$ & 1.7 & 1.07 & 0.28 & 0.44 \\
\hline
\end{tabular}

Table 3. Analysis of Flow to Loads for Sample 6 Bus System

\begin{tabular}{|l|l|l|l|l|}
\hline Line & $\begin{array}{l}\text { Flow } \\
\text { (MW) }\end{array}$ & $\begin{array}{l}\text { Extracted } \\
\text { by Load 4 } \\
\text { (MW) }\end{array}$ & $\begin{array}{l}\text { Extracted } \\
\text { by Load 5 } \\
\text { (MW) }\end{array}$ & $\begin{array}{l}\text { Extracted } \\
\text { by Load 6 } \\
\text { (MW) }\end{array}$ \\
\hline $1-2$ & 29.1 & 14.2 & 11.77 & 3.13 \\
\hline $1-4$ & 43.7 & 21.32 & 17.67 & 4.71 \\
\hline $1-5$ & 35.6 & 17.36 & 14.4 & 3.83 \\
\hline $2-3$ & 3 & 1.21 & 0.69 & 1.11 \\
\hline $2-4$ & 33.3 & 13.37 & 7.61 & 12.32 \\
\hline $2-5$ & 15.5 & 6.22 & 3.54 & 5.74 \\
\hline $2-6$ & 26.4 & 10.6 & 6.03 & 9.77 \\
\hline $3-5$ & 19.3 & 0 & 5.78 & 13.52 \\
\hline $3-6$ & 43.6 & 0 & 13.07 & 30.53 \\
\hline $4-5$ & 4.2 & 3.96 & 0.23 & 0.01 \\
\hline $5-6$ & 1.7 & 0 & 1.66 & 0.04 \\
\hline
\end{tabular}


Electrical \& Computer Engineering: An International Journal (ECIJ) Volume 3, Number 2, June 2014

Table 4. Analysis of Loss to Generators for Sample 6 Bus System

\begin{tabular}{|l|l|l|l|l|}
\hline Line & $\begin{array}{l}\text { Loss } \\
(\mathbf{M W})\end{array}$ & $\begin{array}{l}\text { Supplied } \\
\text { by Gen 1 } \\
(\mathbf{M W})\end{array}$ & $\begin{array}{l}\text { Supplied } \\
\text { by Gen 2 } \\
(\mathbf{M W})\end{array}$ & $\begin{array}{l}\text { Supplied } \\
\text { by Gen 3 } \\
(\mathbf{M W})\end{array}$ \\
\hline $1-2$ & 0.22 & 0.22 & 0 & 0 \\
\hline $1-4$ & 0.26 & 0.26 & 0 & 0 \\
\hline $1-5$ & 0.26 & 0.26 & 0 & 0 \\
\hline $2-3$ & 0.01 & 0 & 0.01 & 0 \\
\hline $2-4$ & 0.38 & 0.14 & 0.24 & 0 \\
\hline $2-5$ & 0.13 & 0.05 & 0.08 & 0 \\
\hline $2-6$ & 0.14 & 0.05 & 0.09 & 0 \\
\hline $3-5$ & 0.29 & 0.01 & 0.01 & 0.27 \\
\hline $3-6$ & 0.25 & 0 & 0.01 & 0.24 \\
\hline $4-5$ & 0.01 & 0.01 & 0 & 0 \\
\hline $5-6$ & 0.01 & 0.01 & 0 & 0 \\
\hline
\end{tabular}

In the MW-Mile method, charges are calculated based on the MW-Miles of network used by each user, ignoring the direction of the power flow in the circuit [34]. It is considered that the cost of the line is based on the impedance of the line. By using Eq. (16), the transmission embedded cost allocation to each participant is done. Different recovery policies for allocating the cost are as follows:-

$100 \%$ cost allocation to all generators.

$100 \%$ cost allocation to all loads.

$50 \%-50 \%$ cost allocation to all generators and loads.

$33 \%-67 \%$ cost allocation to all generators and loads.

$23 \%-77 \%$ cost allocation to all generators and loads.

In this paper, only two policies i.e. $100 \%$ cost allocation to all generators and $100 \%$ cost allocation to all loads is considered. Table 5. and Table 6. show the LODF and MLODF of the sample 6 bus system.

Table 5. LODF of the Sample 6 Bus system

\begin{tabular}{|l|l|l|l|l|l|l|l|l|l|l|l|}
\hline Line & $\mathbf{1}$ & $\mathbf{2}$ & $\mathbf{3}$ & $\mathbf{4}$ & $\mathbf{5}$ & $\mathbf{6}$ & $\mathbf{7}$ & $\mathbf{8}$ & $\mathbf{9}$ & $\mathbf{1 0}$ & $\mathbf{1 1}$ \\
\hline $1-2$ & -1.0 & 0.7 & 1.3 & -0.1 & -0.5 & -0.2 & -0.1 & -0.1 & 0.1 & 0.0 & 0.2 \\
\hline $1-4$ & 0.6 & -1.2 & -0.1 & 0.0 & 0.6 & 0.0 & 0.0 & 0.0 & 0.1 & -0.4 & 0.1 \\
\hline $1-5$ & 0.4 & 0.4 & -3.8 & 0.2 & -0.1 & 0.3 & 0.1 & 0.2 & 0.0 & 0.3 & -0.2 \\
\hline $2-3$ & -0.1 & 0.0 & 6.8 & -1.0 & 0.2 & 0.3 & 4.6 & 0.1 & 0.4 & 0.2 & 0.2 \\
\hline $2-4$ & -0.6 & 0.8 & -1.6 & 0.1 & -1.0 & 0.3 & 0.1 & 0.2 & 0.0 & -0.7 & -0.1 \\
\hline $2-5$ & -0.2 & -0.1 & 1.7 & 0.2 & 0.2 & -1.0 & 0.4 & 0.3 & 0.0 & 0.3 & -0.3 \\
\hline $2-6$ & -0.1 & 0.0 & 0.1 & 0.5 & 0.2 & 0.3 & -1.0 & -0.2 & 0.7 & 0.2 & 0.4 \\
\hline $3-5$ & -0.1 & 0.0 & 0.7 & -0.3 & 0.2 & 0.3 & -0.2 & -1.0 & 0.4 & 0.2 & -0.3 \\
\hline $3-6$ & 0.0 & 0.0 & -1.3 & -0.6 & 0.0 & 0.0 & 0.4 & 0.6 & -1.0 & 0.0 & 0.6 \\
\hline $4-5$ & 0.0 & 0.0 & 6.6 & 0.1 & 0.2 & 0.2 & 0.7 & 0.2 & 0.0 & -1.0 & 0.0 \\
\hline $5-6$ & 0.1 & 0.0 & 4.9 & 0.1 & 0.0 & 0.0 & 5.4 & 0.2 & 0.4 & -0.2 & -1.0 \\
\hline
\end{tabular}


Electrical \& Computer Engineering: An International Journal (ECIJ) Volume 3, Number 2, June 2014

Table 6. MLODF of the Sample 6 Bus System

\begin{tabular}{|l|l|l|l|l|l|l|l|l|l|l|l|}
\hline Line & $\mathbf{1}$ & $\mathbf{2}$ & $\mathbf{3}$ & $\mathbf{4}$ & $\mathbf{5}$ & $\mathbf{6}$ & $\mathbf{7}$ & $\mathbf{8}$ & $\mathbf{9}$ & $\mathbf{1 0}$ & $\mathbf{1 1}$ \\
\hline $1-2$ & -1.3 & 0.5 & 0.6 & 0.0 & -0.5 & -0.1 & -0.1 & -0.1 & 0.1 & 0.0 & 0.0 \\
\hline $1-4$ & 0.8 & -0.7 & 0.5 & 0.0 & 0.7 & 0.0 & 0.0 & 0.0 & 0.0 & 0.0 & 0.0 \\
\hline $1-5$ & 0.5 & 0.3 & -0.9 & 0.0 & -0.1 & 0.1 & 0.1 & 0.1 & 0.0 & 0.0 & 0.0 \\
\hline $2-3$ & -0.1 & 0.0 & 0.2 & -0.1 & 0.2 & 0.1 & 0.3 & 0.1 & 0.3 & 0.0 & 0.0 \\
\hline $2-4$ & -0.7 & 0.6 & -0.2 & 0.0 & -1.1 & 0.2 & 0.1 & 0.1 & 0.0 & -0.1 & 0.0 \\
\hline $2-5$ & -0.2 & -0.1 & 0.3 & 0.0 & 0.3 & -0.6 & 0.2 & 0.2 & 0.0 & 0.0 & 0.0 \\
\hline $2-6$ & -0.1 & 0.0 & 0.2 & 0.1 & 0.2 & 0.2 & -0.6 & -0.1 & 0.5 & 0.0 & 0.0 \\
\hline $3-5$ & -0.1 & 0.0 & 0.2 & 0.0 & 0.2 & 0.2 & -0.1 & -0.6 & 0.3 & 0.0 & 0.0 \\
\hline $3-6$ & 0.0 & 0.0 & 0.0 & -0.1 & 0.0 & 0.0 & 0.4 & 0.3 & -0.7 & 0.0 & 0.0 \\
\hline $4-5$ & 0.0 & 0.0 & 0.3 & 0.0 & 0.2 & 0.1 & 0.1 & 0.1 & 0.0 & -0.1 & 0.0 \\
\hline $5-6$ & 0.1 & 0.0 & 0.1 & 0.0 & 0.0 & 0.0 & 0.2 & 0.1 & 0.3 & 0.0 & 0.0 \\
\hline
\end{tabular}

Table 7. and Table 8. show the cost allocation to each generator and load under contingency condition due to LODF and MLODF respectively. Figure 3. and Figure 4. show the total cost allocation to generator and load due to both distribution factors respectively. It is clear that the cost allocation is more in case of MLODF in each line.

Table 7. Analysis of Cost Allocation to Different Generators

\begin{tabular}{|l|l|l|l|l|l|l|}
\hline \multirow{2}{*}{ Line } & \multicolumn{3}{|l|}{$\begin{array}{l}\text { Cost Allocated due to } \\
\text { LODF } \mathbf{( \$ / h r )}\end{array}$} & \multicolumn{3}{l|}{$\begin{array}{l}\text { Cost Allocated due to } \\
\text { MLODF } \mathbf{( \$ / h r )}\end{array}$} \\
\cline { 2 - 7 } & G1 & G2 & G3 & G1 & $\mathbf{G 2}$ & G3 \\
\hline $1-2$ & 87.98 & 0 & 0 & 128.07 & 0 & 0 \\
\hline $1-4$ & 140.4 & 0 & 0 & 135.66 & 0 & 0 \\
\hline $1-5$ & 204.0 & 0 & 0 & 216.30 & 0 & 0 \\
\hline $2-3$ & 1.157 & 1.9844 & 0 & 17.197 & 29.481 & 0 \\
\hline $2-4$ & 20.17 & 34.663 & 0 & 24.021 & 41.262 & 0 \\
\hline $2-5$ & 23.96 & 41.164 & 0 & 68.485 & 117.623 & 0 \\
\hline $2-6$ & 37.32 & 64.100 & 0 & 43.057 & 73.938 & 0 \\
\hline $3-5$ & 2.263 & 3.9286 & 122.51 & 2.8868 & 5.0094 & 156.2 \\
\hline $3-6$ & 1.285 & 2.2031 & 69.366 & 1.4306 & 2.4526 & 77.22 \\
\hline $4-5$ & 5.954 & 2.2727 & 0 & 103.9 & 39.663 & 0 \\
\hline $5-6$ & 1.9173 & 0.501748 & 0.7884 & 22.109 & 5.7856 & 9.0917 \\
\hline Total & 526.53 & 150.820 & 192.67 & 763.14 & 315.217 & 242.53 \\
\hline
\end{tabular}

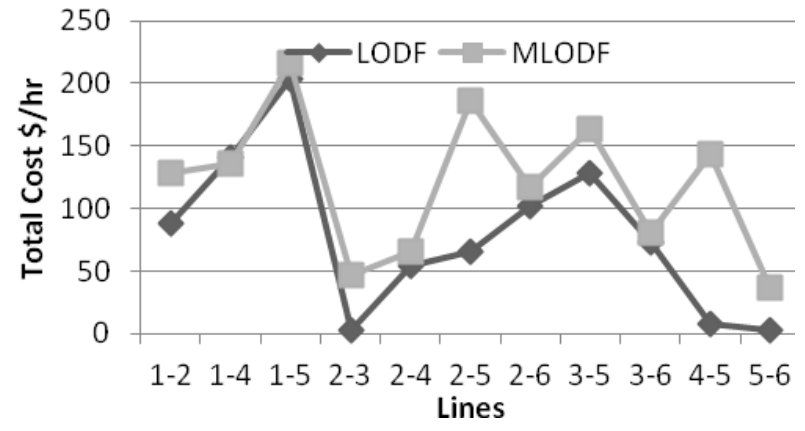

Figure 3. Total cost allocation to generator due to LODF and MLODF 
Electrical \& Computer Engineering: An International Journal (ECIJ) Volume 3, Number 2, June 2014

Table 8. Analysis of Cost Allocation to Different Loads

\begin{tabular}{|c|c|c|c|c|c|c|}
\hline \multirow[t]{2}{*}{ Line } & \multicolumn{3}{|c|}{$\begin{array}{l}\text { Cost Allocated due to } \\
\text { LODF }(\$ / h r)\end{array}$} & \multicolumn{3}{|c|}{$\begin{array}{l}\text { Cost Allocated due to } \\
\text { MLODF }(\$ / h r)\end{array}$} \\
\hline & L4 & L5 & L6 & L4 & L5 & L6 \\
\hline $1-2$ & 42.371 & 36.3 & 9.080 & 61.680 & 52.868 & 13.217 \\
\hline $1-4$ & 67 & - & 16 & 6 & & \\
\hline $1-5$ & 6 & 80 & & 10 & & \\
\hline $2-3$ & \begin{tabular}{|l}
1.034 \\
\end{tabular} & 1.034 & 1.0 & 15. & & \\
\hline $2-4$ & 21.156 & 13.019 & 19 & 25. & & 23.246 \\
\hline $2-5$ & 24.9 & 16. & 24. & 71.216 & 47.477 & 71.216 \\
\hline $2-6$ & 41.772 & 22.785 & 37.975 & 48.183 & 26.282 & 43.803 \\
\hline $3-5$ & 0.000 & 39.952 & 93.222 & 0.000 & 50.944 & 118.87 \\
\hline $3-6$ & \begin{tabular}{|l|}
0.000 \\
\end{tabular} & 21.6 & 51.741 & 0.000 & 24.154 & 57.599 \\
\hline $4-5$ & \begin{tabular}{|l}
7.513 \\
\end{tabular} & 0.000 & 0.000 & 131.12 & 0.000 & 0.000 \\
\hline $5-6$ & 0.0 & & & 0.000 & 41.327 & 0.000 \\
\hline Total & 303.87 & 293.24 & 276.54 & 521.400 & 414.999 & 383.174 \\
\hline
\end{tabular}

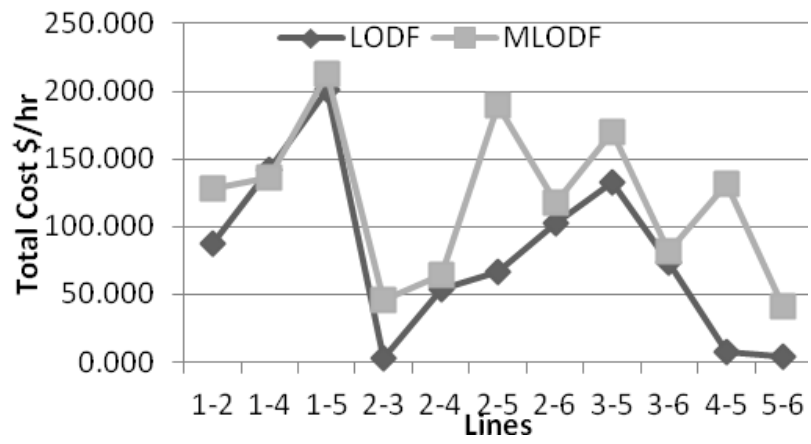

Figure 4. Total cost allocation to load due to LODF and MLODF. Table 9. Analysis of Loss Cost Allocation to Different Generators

\begin{tabular}{|l|l|l|l|l|l|l|}
\hline \multirow{2}{*}{ Line } & \multicolumn{3}{|l|}{$\begin{array}{l}\text { Loss Cost Allocated } \\
\text { due to LODF } \mathbf{( \$ / h r )}\end{array}$} & \multicolumn{2}{l|}{$\begin{array}{l}\text { Loss Cost Allocated } \\
\text { due to MLODF } \mathbf{( \$ / h r ) ~}\end{array}$} \\
\cline { 2 - 7 } & G1 & G2 & G3 & G1 & G2 & G3 \\
\hline $1-2$ & 0.883 & 0.000 & 0.000 & 3.444 & 0.000 & 0.000 \\
\hline $1-4$ & 0.893 & 0.000 & 0.000 & 3.354 & 0.000 & 0.000 \\
\hline $1-5$ & 2.457 & 0.000 & 0.000 & 5.105 & 0.000 & 0.000 \\
\hline $2-3$ & 0.000 & 0.892 & 0.000 & 0.000 & 0.000 & 0.000 \\
\hline $2-4$ & 0.243 & 0.417 & 0.000 & 0.678 & 1.162 & 0.000 \\
\hline $2-5$ & 0.922 & 1.476 & 0.000 & 1.826 & 2.922 & 0.000 \\
\hline $2-6$ & 0.148 & 0.267 & 0.000 & 1.156 & 2.081 & 0.000 \\
\hline $3-5$ & 0.077 & 0.077 & 2.082 & 0.165 & 0.165 & 4.461 \\
\hline $3-6$ & 0.000 & 0.040 & 0.952 & 0.000 & 0.065 & 1.555 \\
\hline $4-5$ & 0.522 & 0.000 & 0.000 & 0.000 & 0.000 & 0.000 \\
\hline $5-6$ & 0.316 & 0.000 & 0.000 & 2.095 & 0.000 & 0.000 \\
\hline Total & 6.462 & 3.169 & 3.033 & 17.823 & 6.395 & 6.016 \\
\hline
\end{tabular}




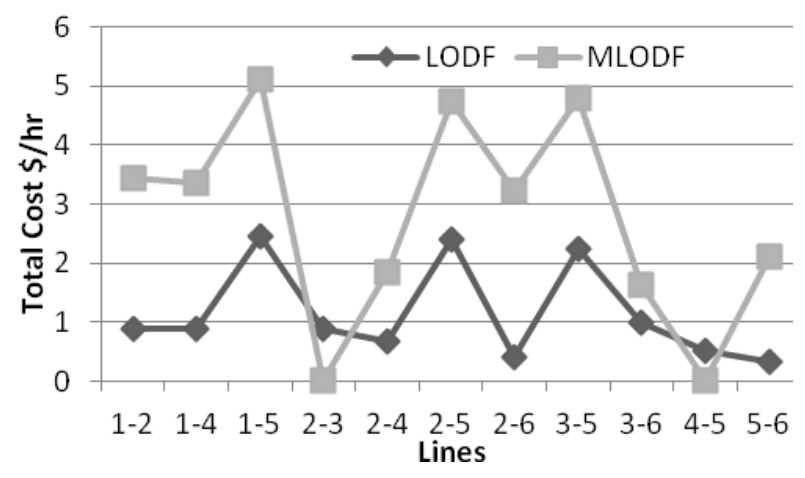

Figure 5. Total loss cost allocation to generator due to LOLDF and MLOLDF.

Table 9. shows the loss cost allocation to each generator under contingency condition due to LOLDF and MLOLDF. Figure 5. shows the total loss cost allocation to generator due to both distribution factors.

\section{CONCLusion}

In this paper, authors have presented a combined methodology for the transmission usage cost and loss allocation. Modified Matrix methodology [7] is used to trace the power flow to different loads. MW-Mile method is used to allocate the cost. The calculation of pline and distribution factors are time taking. Moreover, it is demonstrated that the proposed method is more accurate and feasible. It is clear that the transmission usage cost allocation and loss allocation considering MLODF and MLOLDF is more as compared to LODF and LOLDF as observed from Fig 2, Fig 3 and Fig 4. Results are shown for the sample 6 bus system.

\section{REFERENCES}

[1] D. Shrimohammadi et al., " Evaluation of transmission network capacity use for wheeling transactions," IEEE trans. On Power Systems, vol. 4, no. 4 pp. 1405-1413, Oct. 1989.

[2] D. Shrimohammadi et al. , "Cost of transmission transactions: An introduction," IEEE Trans. on Power Systems, vol. 6, no. 4 pp. 1546-1560, Nov. 1991.

[3] H.H. Happ, “ Cost of wheeling methodologies," IEEE Trans. on Power Systems, vol. 10,no. 2,pp. 1125 - 1142, May 1995.

[4] J.W. Marangon Lima, “Allocation of transmission fixed charges:, An overview," IEEE Trans on Power Systems, vol. 11, no. 3, pp. 1409 - 1418, Aug 1996.

[5] R.R.Kovacs and A.L. Leverett, " A load flow based method for calculating embedded, incremental and marginal cost of transmission capacity,” IEEE Trans on Power Systems, vol. 9, no. 1, pp. 272 278, Feb 1994.

[6] Baseem Khan, Ganga Agnihotri and Gaurav Gupta, "A Multipurpose Matrices Methodology for Transmission Usage, Loss and Reliability Margin Allocation in Restructured Environment", Electrical \& Computer Engineering: An International Journal (ECIJ) Vol 2, No 3, Sept. 2013.

[7] Baseem Khan, Ganga Agnihotri, Gaurav Gupta, Pawan Rathore, Garima Naidu, "Reliability Indices Approach for Transmission Usage, Loss and Reliability Margin Cost Allocation under N-1 Contingent Restructured Market", Wulfenia Journal, Volume. 21, Issue. 2, 2014, ISSN No: 1561$882 \mathrm{X}$

[8] Thukaram D., Vyjayanthi C., "Ranking of Prospective New Generation Location for a Power Network in a Deregulated System," Joint International Conference on Power System Technology (POWERCON 2008), pp.1-8, 12-15 Oct. 2008. 
[9] Thukaram D., Vyjayanthi C., "Evaluation of Charges for Power Transmission and Losses in Bilateral Power Contracts," TENCON 2008, pp.1-6, 19-21 Nov. 2008.

[10] D. Thukaram, C. Vyjayanthi, "Relative Electrical Distance Concept for Evaluation of Network Reactive Power and Loss Contributions in a Deregulated System”, IET Gener. Transm. Distrib., Vol. 3, Iss. 11, pp. 1000-1019, 2009.

[11] Tsukamoto, Y., and Iyoda, I., "Allocation of fixed transmission cost to wheeling transactions by cooperative game theory,” IEEE Trans. Power Syst., Vol. 11, No. 2, pp. 620-629, May 1996.

[12] Yu, C. W., David, A. K., and Wong, Y. K., "The use of game theory in transmission embedded cost allocation," 5th International Conferenceon Advancesin Power System Control, Operation and Management, pp. 139-143, Hong Kong, October 2000.

[13] Tan, X., and Lie, T. T., "Application of the Shapley value on transmission cost allocation in the competitive power market environment," IEE Proc. Generat. Transm. Distrib., Vol. 149, No. 1, pp. 15-20, January 2002.

[14] Zolezzi, J. M., and Rudnick, H., "Transmission cost allocation by cooperative games and coalition formation,” IEEE Trans. Power Syst., Vol. 17, No. 4, pp. 1008-1015, November 2002.

[15] Yu, C. W., David, A. K., Tse, C. T., and Chung, C. Y., "Capacity-use and reliability based transmission embedded cost allocation with temporal considerations," Int. J. Elect. Power Energy Syst., Vol. 25, pp. 201-208, 2003.

[16] Stamtsis, G. C., and Erlich, I., "Use of cooperative game theory in power system fixed-cost allocation,” IEE Proc. Generat. Transm. Distrib., Vol. 151, No. 3, pp. 401-406, May 2004.

[17] Happ, H. H., "Cost of wheeling methodologies," IEEE Trans. Power Syst., Vol. 9, No. 1, pp. 147156, February 1994. 2. Young, H. P., "Cost allocation," in Handbook of Game Theory Vol. 2, R. J. Aumann and S. Hart (Eds.), Amsterdam: Elsevier Science B. V., pp. 1193-1235, 2004

[18] GeorgeA. Orfanos, PavlosS. Georgilakis and NikosD. Hatziargyriou, "A More Fair Power Flow Based Transmission Cost Allocation Scheme Considering Maximum Line Loading for N-1 Security", IEEE Transactions on Power Systems, Vol.28, No.3, August2013.

[19] J. Bialek, D. B. Tam, "Tracing The Generators' Output”, Opportunities and Advances in International Power Generation, 18-20th March 1996.

[20] J. Bialek, "Topological Generation and Load Distribution Factors for Suppliment Charge Allocation in Transmission Open Access", 'I, IEEE Transactions on Power Systems, Vol. 12, No. 3, August 1997 pp,1185-1193.

[21] Daniel Kirschen, Ron Allan, Goran Strbac, "Contributions of Individual Generators to Loads and Flows”, IEEE Transactions on Power Systems, Vol. 12, No. 1, February 1997.

[22] Ferdinand Gubina, David Grgi cc, Ivo Bani, "A Method for Determining the Generators' Share in a Consumer Load", IEEE transactions on power systems, vol. 15, no. 4, November 2000.

[23] Felix F. Wu, Yixin Ni, and Ping Wei, "Power Transfer Allocation for Open Access Using Graph Theory - Fundamentals and Applications in Systems without Loop flow", IEEE transactions on power systems, vol. 15, no. 3, august 2000.

[24] Kaigui Xie, Jiaqi Zhou, Wenyuan Li, "Analytical model and algorithm for tracing active power flow based on extended incidence matrix" Electric Power Systems Research 79 (2008) 399-405.

[25] Antonio J. Conejo, Javier Contreras, Delberis A. Lima, Antonio Padilha-Feltrin, "Z-bus Transmission Network Cost Allocation”, IEEE transactions on power systems, vol. 22, no. 1, February 2007.

[26] A. R. Abhyankar, S. A. Soman, S. A. Khaparde, "Optimization Approach to Real Power Tracing: An Application to Transmission Fixed Cost Allocation", IEEE transactions on power systems, vol. 21, no. 3, august 2006.

[27] Rao M.S.S., Soman S.A., Chitkara P., Gajbhiye R.K., Hemachandra N., Menezes B.L., "Min-Max Fair Power Flow Tracing for Transmission System Usage Cost Allocation: A Large System Perspective", IEEE Transactions on Power Systems, Vol. 25, no. 3, pp. 1457-1468, Aug. 2010.

[28] P. N. Biskas and A. G. Bakirtzis, "Decentralised security constrained DCOPFofinterconnectedpowersystems,"Proc.IEEGener.Transm. Distrib., vol. 151, no. 6, pp. 747-754, 2004.

[29] Silva E.L., Mesa S.E.C., Morozowski. M.: 'Transmission access pricing to wheeling transactions: a reliability based approach', IEEE Trans. Power Syst., 1998, 13, (4), pp. 1481-1486.

[30] D. Hur, C.-I. Yoo, B.H. Kim and J.-K. Park, "Transmission embedded cost allocation methodology with consideration of system reliability”, IEE Proc.-Gener. Transm. Distrib., Vol. 151, No. 4, July 2004. 
[31] V. Vijay Venu, A. K. Verma, "A probabilistic transmission pricing methodology considering transmission reliability margins", Int J Syst Assur Eng Manag (Apr-June 2010) 1(2):113-119.

[32] Monsef H, Jaefari M, "Transmission cost allocation based on use of reliability margin under contingency conditions”, IET Gener Transm, Distrib 3(6):574-585.Electronic Publication: Digital Object Identifiers (DOIs)

[33] K.-H. Chung, B. H. Kim, D. Hur, and J.-K. Park, "Transmission re- liability cost allocation method based on market participants' reliability contribution factors,'Electr.PowerSyst.Res.,vol.73,no.1,pp. 31-36, Jan.

[34] Z.Jing,X.Duan,F.Wen,Y.Ni,andF.F.Wu,"Review of transmission fixed cost allocation methods,"inProc. IEEE Power Eng. Soc.General Meeting, Toronto, on, Canada, 2003.

[35] R. D. Christie, B. F. Wollenberg, and I. Wangensteen, "Transmission management in the deregulated environment,"Proc.IEEE,vol.88,no. 2, pp. 170-195, Feb. 2005

\section{Authors}

Pawan Rathore was born in Balco Town, Korba City, Chhattisgarh State, India in 1990. He received the B.E. degree in Electrical and Electronics engineering from Chhattisgarh Swami Vivekananda Technical University, Bhilai in 2012. Currently, he is pursuing M.Tech from Maulana Azad National Institute of Technology, Bhopal. His research interests include power system optimization, congestion management, transmission pricing and application of artificial intelligence techniques in power system.

Garima Naidu was born in Bhopal, Madhya Pradesh State, India in 1989. She received her B.Tech degree in Electrical and Electronics engineering from Vellore Institute of Technology, Vellore, Tamil Nadu in 2012. Currently, she is pursuing M.Tech from Maulana Azad National Institute of Technology, Bhopal. Her research interests include power system optimization, FACTS devices, and application of artificial intelligence techniques in power system.

Ganga Agnihotri received BE degree in Electrical engineering from MACT, Bhopal (1972), the ME degree (1974) and PhD degree (1989) from University of Roorkee, India. Since 1976 she is with Maulana Azad College of Technology, Bhopal in various positions. Currently she is professor. Her research interest includes Power System Analysis, Power System Optimization and Distribution Operation.
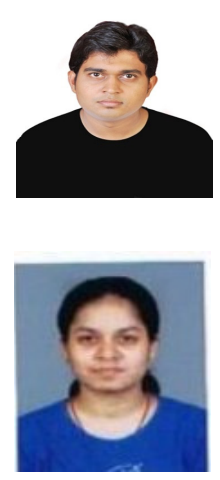

Baseem Khan was born in Gwalior, India in 1987. He received BE degree (2008) from Maharana Pratap College of Technology Gwalior and received an M.Tech. degree (2010) in Power System from MANIT Bhopal. At the moment he is a research scholar at MANIT Bhopal, India. His research interests include power system optimization, congestion management, transmission pricing and application of artificial intelligence techniques in power system.
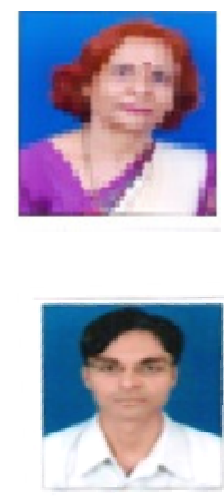